\title{
Radiation Emission Levels From Monitor Screens of Some Residential and Office Electronic Equipments within A University Community in Nigeria
}

\author{
R.O.K. Meindinyo ${ }^{1}$, G. Ogobiri ${ }^{2}$, E.O. Agbalagba ${ }^{3}$ \\ ${ }^{1,2}$ Niger Delta University, Wilberforce Island, Bayelsa State, Nigeria. \\ ${ }^{3}$ Department of Physics, University of Port Harcourt, Rivers State, Nigeria.
}

\begin{abstract}
A study of the possible exposure to ionizing radiation from home viewing monitors and office computer monitor screens at normal distances of $0.5 \mathrm{~m}$ and $1.0 \mathrm{~m}$ and the environmental background level within university of Port Harcourt, Nigeria has been carried out using 18 different models of computer monitors and 15 deferent models of television sets. Radiation measurements were carried out insitu using Digilert 50 nuclear radiation monitor (SE INTERNATONAL INC, SUMMER TOWN USA) which is optimized to measure average exposure rate. The measured exposure rate ranged between $08.00 \pm 0.80 \mu R h^{-1}(3.56 \pm 0.36 \mu \mathrm{Sv} /$ week) to $20.00 \pm 3.20 \mu R h^{-1}\left(8.90 \pm 1.42 \mu \mathrm{Sv} /\right.$ week) for computer monitors and $11.00 \pm 1.20 \mu R h^{-1}(5.26 \pm 1.00 \mu \mathrm{Sv} /$ week) to $23.00 \pm 4.40 \mu R h^{-1}\left(10.24 \pm 1.96 \mu S v /\right.$ week) for television sets, with B.I.R level range of $6.00 \mu R h^{-1}$ to 13.00 $\mu \mathrm{Rh}^{-1}$. Dell computer monitors and 21 "Toshiba television sets have the respective highest exposure rate. Samsung computer monitors and television sets were observed to emit the lowest amount of radiation and considered safest among the investigated products. A comparison of radiation from the computer monitors and television sets show that television sets emit more ionizing radiation than computers monitors. The overall result shows that the average exposure rate obtained are within the radiation limit of $0.2 \mathrm{mSv} /$ week recommended by ICRP, thus computer operators and television viewers using those models are exposed to radiation levels that may not be hazardous.
\end{abstract}

Keyword: Radiation level, computer monitor television screens, university community.

\section{Introduction}

There is continuous exposure of man to ionizing and non ionizing radiation due to natural and artificial sources of radiation. (Agbalagba et al and R.O.K Meindinyo et al 2017). Over 60 radioactive elements can be found in nature and they can be placed in three general categories: Primordial-formed as a result of cosmic ray interaction and artificial radionuclide-formed due to human actions and activities (Eyebiokin et al. 2005).

In recent times, a large number of research efforts have been directed on the effects of ionizing radiation of X-rays on the structural properties of tissues, organs and bones from radiographic examinations. Reasons have been that it is classified as the known highest artificial radionuclide contributor to the natural background radiation levels. Whereas, less research effort is been dedicated on other consumer products such as luminous wrist watches, florescent bulbs, paints, computer screens, television sets etc which also emit artificial ionizing radiation (Mokobia et al. 1998).

Computer systems and televisions are fast becoming a must own appliances in all homes and offices throughout the country. They are found almost in all companies, industries, research institutions, telecommunication sector and homes. In institutions like the university Port Harcourt, computer systems are found in almost every office and business centers. People spend quality time working with these systems while in the office and spend good time at home or/and in clubs watching television news and programmes thereby exposed to ionizing radiation. The accumulative dose effects from the dual artificial source of radiation due to long exposure period, ;if properly quantify may be equal if not greater than other widely publicized instantaneous exposure to $\mathrm{X}$ - ray radiation.

Inconclusive studies (Updegrove and Updegrove, 1991) have been made as to whether there are health hazards associated with the use of computer systems. However, these studies have not proved as some would believe that no potential health hazards from computer display terminal exist. It could easily be argued however that the inconclusiveness of these studies is an indication to the facts that, there could be health risks associated with thse system. Agba and Ayangeakaa (2005), investigated the radiation levels from computer monitor screens within Benue State University. The result shows that the computer operators using the models investigated were working within recommended safety radiation limits of $0.02 \mathrm{mSv} /$ week as prescribed by ICRP. A study carried out in Sweden, found a correlation between computer monitors and the health of those using them (Steadman and Hodgkinson, 1990). The outcome of this study has become a critical factor in the rating of computers with low levels of radiation mark (Agba abd Ayaneakaa, 2005). 
Measurement of the radiation exposure rate from television sets has been carried out in a number of countries the last known survey has being that done, in Germany and Asia.

In Nigeria Mokobia et. al. (1998) measured the radiation exposure rate from one hundred television sets in Abraka, and reported a mean value of $0.016 \pm 0.001 \mathrm{mRh}^{-1}$ and concluded that the value obtained represent just $32 \%$ of the value recommended by ICRP. It is therefore worth emphasizing that there are possible present of radiation (soft $\mathrm{X}$-ray) as a by-product from television and computer monitor.

Since various source of ionizing radiation (natural and artificial) can lead to internal and external human exposures. There is the need for a precise knowledge of the levels of activity of the various radionuclides in the environment we are exposed to. In recent tiomes, the measurement of natural backgroung radiation levels has assured significance, mainly due to the fact that nature constitutes the largest source of radiation exposed to the general public (UNSCEAR, 1993). It is thus necessary to know the background radiation levels in the determining the exposure rate these radiation producing machines.

This work will examine the actual radiation emitted from the screen by considering the background radiation levels. More so, civilization has made man a regular guest of the television set with them, thus increasing man's exposure rate and absorption dose rate these from radioactive elements. The study will therefore examine the equipment dose rate per week from these machines. Furthermore, a comprehensive analysis of the equivalent dose rate between the television sets and computer monitors will also be examined. This survey work will therefore avail the public especially computer operators and television viewers the opportunity to know the level of radiation they are exposed to, while appropriate recommendation will be made to reduce and abate possible increase.

\section{Materials And Method}

This was conducted in May 2005, within the three campuses of the University of Port Harcourt. The study area lies in within longitude $006^{\circ}$ and latitude $04^{0} 54 \mathrm{~N}$ of Rivers State.

An institu approach of radiation measurement was adopted, using diligert 50 nuclear radiation monitor (S.E International, Inc. Summer town, USA) containing a Geiger Muller tube capable of detecting $\alpha, \beta, \alpha$ and X-ray within the temperature range of -10 to $50 \infty 18$ different make of 15 different models of computer screens and 9 different make of 15 different models of television sets of various sizes were investigated within three campuses of Uniport.

Measurements were taken in the morning, afternoon and night between the hours of 0800-1100, 13001600 and 200-2300 respectively and the average of values and standard errors obtained. Readings were taken at 0.5 meters and 1.0 meters distance from source. This represents man - screen distance or normal viewing position of computer and television set.

The tube of the radiation monitoring meter was raised to a standard height of $1.0 \mathrm{~m}$ above the ground (Agbalagba and R.O.K.Meindinyo 2013) with its window facing the screen while the systems are in use.

To know the health hazard for computer operators and television viewers at these ranges, the average equivalent dose rate per week was calculated. Using the expression (Agbalagba et. al 2007). $1 \mathrm{mRh}^{-1}=0.445 \mathrm{mSv} /$ week

\section{Result And Discussion}

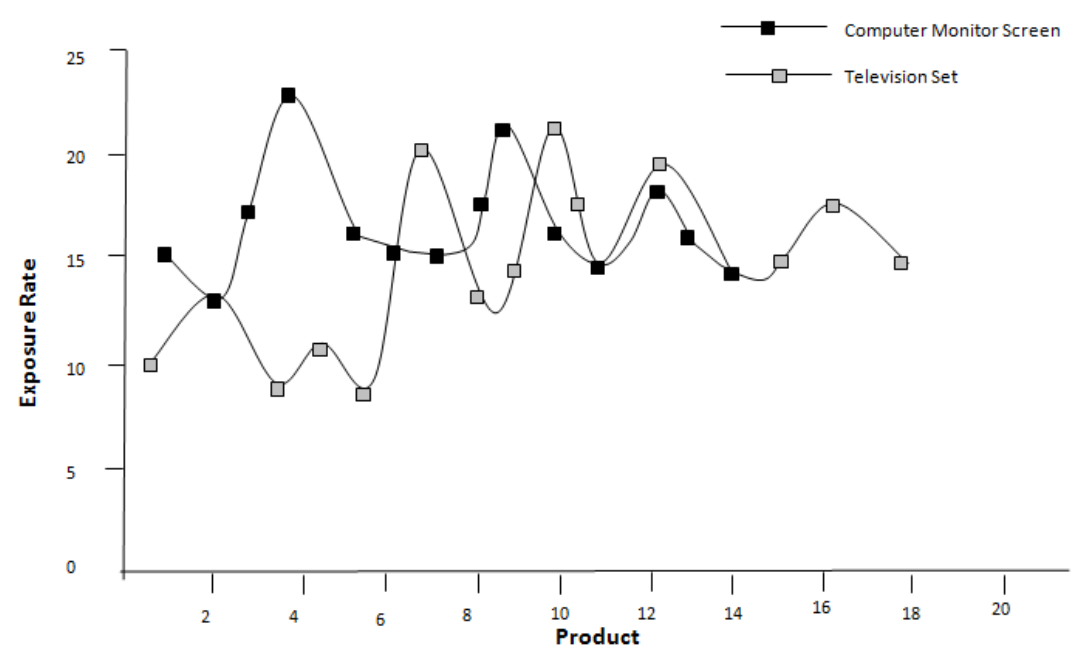

Fig 1: Comparison of exposure rate $\left(\mu \mathrm{Rh}^{-1}\right)$ of television set and computer monitors at $0.5 \mathrm{~m}$ distance 


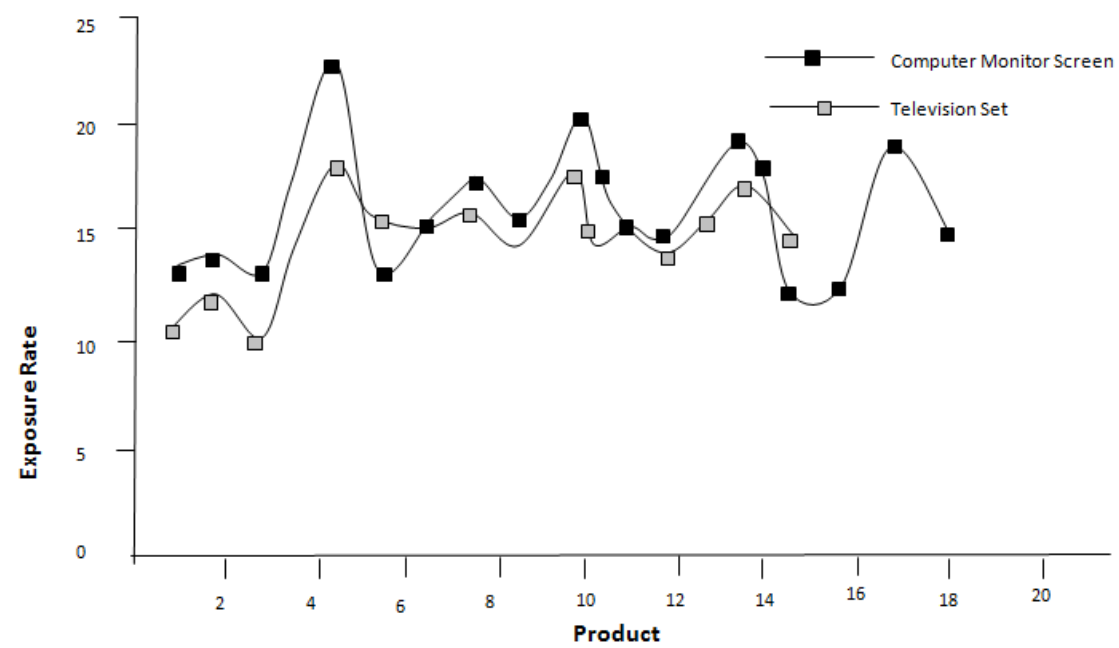

Fig 2: Comparison of exposure rate $\left(\mu \mathrm{Rh}^{-1}\right)$ of television set and computer monitors at $1 \mathrm{~m}$ distance

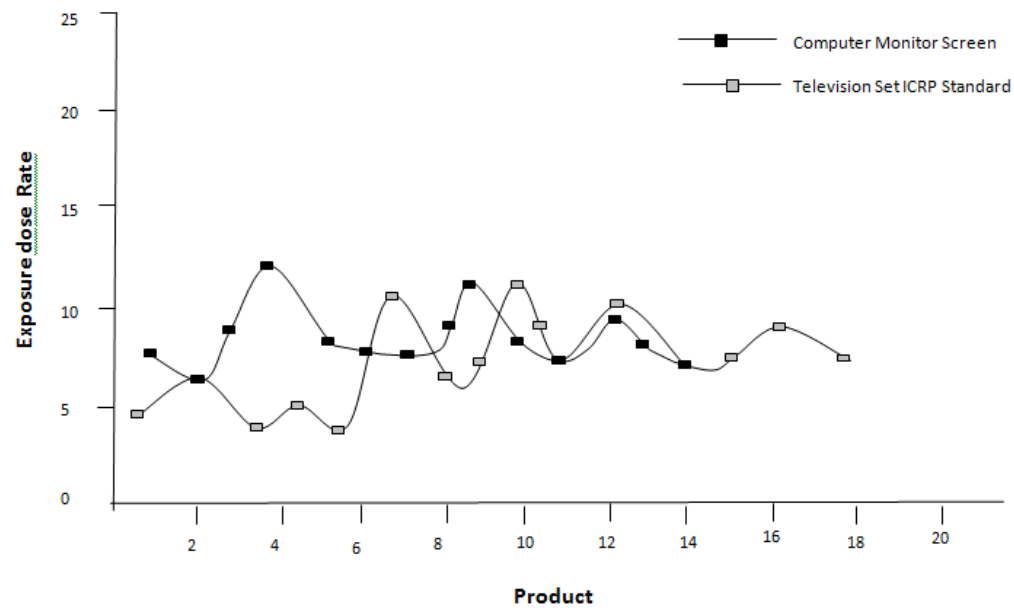

Fig 3: Comparison of Equivalent dose Rate ( $\mu \mathrm{Sv} /$ week) of television set and computer monitors at $0.5 \mathrm{~m}$ distance with ICRP standard.

The results obtained are graphically display in figure 1,2 and 3. The results are from the measured parameters of activity (CPM), composure rate ( $\mu \mathrm{Sv} / \mathrm{week})$. The conversion from count per minute (CPM) to exposure rate then to equivalent dose rate was on the basis of 8 working hours a day for 6 days a week. The average values obtained for the 18 computer monitors examined ranges from $11.0 \pm 1.00 \mu \mathrm{Rh}^{-1}(4.90 \pm 0.45$ $\pm \mu \mathrm{Sv} / \mathrm{wk})$ for $0.5 \mathrm{~m}$ distance from source and ranges from $0.800 \pm 0.80 \mu \mathrm{Rh}^{-1}(3.56 \pm 0.36 \mu \mathrm{Sv} / \mathrm{wk})$ for $1.0 \mathrm{~m}$ distance from screens, while the B.I.R levels ranges between $6.00 \mu \mathrm{Rh}^{-1}$ to $12.00 \mu \mathrm{Rh}^{-1}$. This shows a remarkable dose decrease with distance from the source as should be expected.

The average values obtained for the 15 television sets measured, ranges from $14.00 \pm 1.60 \mu \mathrm{Rh}^{-1}$ $(6.23 \pm 0.71 \mu \mathrm{Sv} / \mathrm{wk})$ to $23.00 \pm 4.40 \mu \mathrm{Rh}^{-1}(10.24 \pm 1.96 \mu \mathrm{Sv} / \mathrm{wk})$ for $0.5 \mathrm{~m}$, distance from TV sets and ranges from $11.00 \pm 1.20 \mu \mathrm{Rh}^{-1}(4.90 \pm 0.53 \mu \mathrm{Sv} / \mathrm{wk})$ to $16.00 \pm 2.70 \mu \mathrm{Rh}^{-1}(7.12 \pm 1.20 \mu \mathrm{Sv} / \mathrm{wk})$ for $1.0 \mathrm{~m}$ distance from TV sets. This result also shows a significant dose decrease with distance from the source. These values obtained in this work have confirmed the presence of radiation emission from these 18 computer monitors and the 15 TV sets investigated within the University of Port Harcourt. Slight variations in the measured radiation parameters from the difference computer monitors and television sets also been observed. This may possibly be due to the difference anode voltage used in accelerating the electron beam and the age of the system monitors and TV sets. It may also attribute to the nature of materials used in the manufacturing of computers systems and TV sets.

In order to have a clearer comparison of the different levels of radiation emitted from the computer monitors and the television sets, a plot of exposure rate of computer monitor screens and TV sets shown in figures 1 and 2. Theobtained results shows at a glance, that radiation levels emitted from TV sets is higher than the levels emitted from computer monitor. This may be attributal to the renewed concern given to improved design of computer monitors that will ergonomically be user friendly. In addition the study revealed that the television screen size has no effect on the amount of radiation emitted. Figure 3 shows the comparison of the dose rate at the distance of $0.5 \mathrm{~m}$ for TV sets and computer monitor with ICRP standard. Despite the presence of these 
radiation levels from all the investigated computer monitors and TV sets, the operators and viewers are still working within the safe recommended equivalent dose limit of $0.02 \mathrm{SV} /$ week for the public; since computer operators and TV viewers are consider as non-radiation workers.

\section{Conclusion}

A comparative study of radiation levels from computer monitors and television set screens within University of Port Harcourt have been carried out. The work has confirmed the presence of radiation from the computer screens and television sets screens beyond the normal background radiation levels. The highest equivalent doses rate of $0.0089 \mathrm{mSv} / \mathrm{week}$ is obtained for "Dell computer monitor and $0.01024 \mathrm{mSv} / \mathrm{week}$ for 21 " Toshiba television sets. The Samsung computer monitor and Samsung television are considered as the safest computer monitor and television set among the products investigated, since they emits the lowest amount of radiation.

Despite the presence of radiations from these consumer products, all operators of the various products of computer monitor and television screens investigate are working within safe radiation environment, even when set at a distance of $0.5 \mathrm{~m}$ from the sources. However, caution must be exercise against spending too long a time with these consumer products as its long accumulative effects is still under investigation. Moreso, the equivalent dose rate for eye (organ) is below the whole body recommended standard for ICRP, thus amount of man hours on these product should be reduce to avoid future eye related problem.

\section{References}

[1] Agba,E.A and D.A Ayangeakaa, 2005. Radiation levels from computer monitor screens within Benue State University Nigeria. J. Physic 17:46-49.

[2] Agbalagba O.E. G.O Avwiri and P.I Enyinna, 2008. Assignment of natural radioactivity concentration and distributionin Rivers Forcades, Delta State, Nigeria Scientia Africana. 7(1):128-125.

[3] Agbalagba O.E, G.O Avwiri and P.I Enyinna, 2007. Terrestrial Radiation Around oil and gas facilities in Ugheli, Nigeria. J Appl Sc 7(ii): 1543 - 1546.Asian network for Sc. Infor.

[4] Agbalagba E.O. and Meindinyo R.O.K, Radiological impact of oil spillage on production land in Niger Delta Region, International Journals of Environmental Sciences Volume 5, Number 3, Pages 102-106.(2013)

[5] Meindinyo R.O.K, Agbalagba E.O, and Olali S.A.(2017) Assessment of radionuclide contents in some common brands of cement used in Nigeria. ISOR journals in research and Method in Education Volume 7, Number 5, page 114-119.

[6] Eyebiokin M.R, M.A Arogunjo, F.A Balogun and A.G Rabiu., 2005Activity concentrations and absorbed dose equivalent of commonly consumed vegetables in Ondo State Nigeria Nig. J. of Phys 17(5): $187-191$.

[7] International Commission on Radiological Protection (ICRP), 1991. The 1990-91 recommendation of the International Commission on Radiological protection publication 60. Ann ICRP 21 (1-3).

[8] John, V.M and S.E Zordan, 2001, Research and Methodology for recycling residues as building materials, a proposed waste management 7:213-219.

[9] Mokobia C.E, E.C Okolie and E. Atapko, 1998 measurement of Radiation Exposure rate from television sets in Abraka, Delta State Steadman, P. and S. Hodgkinson, 1990. Nuclear disaster and the building environment. Esevier science and technology books. UK.

[10] UNSCEAR, 1993. United Nation, source and effects Atomic Radiation, 1993. Report to the General Assembly, with scientific Annexe, United Nations, New York 1993: 9922.

[11] Updegrove, D.A and K.U Updegrove 1991. Computers and Health. Individual and institutional protective measures.Newsletter Vol.111, University of Pennsylavania. 